\title{
A case of inaugural hyperosmolar diabetic coma reported from Côte d'Ivoire
}

\author{
DERE Kwadjo A. L ${ }^{1, *}$, Kouame Andre B ${ }^{2}$, KOFFI Konan G. ${ }^{3}$, MANHAN Kahissié ${ }^{4}$, TIAHOU G. George ${ }^{5}$ \\ ${ }^{1,3,5}$ M.D, Biologist, ${ }^{2,4}$ M.D, Interne in Medicine, Unit of Training and Research, Medical School Bouaké, Côte d'Ivoire
}

*Corresponding Author:

Email: dere.kwadjoanicetluc@gmail.com

Received: $21^{\text {st }}$ January, 2018

Accepted: $7^{\text {th }}$ March, 2018

\begin{abstract}
A forty eight years old man was brought into the hospital in a deeply comatose and dehydrated state. In Côte d'Ivoire, few works related to hyperosmolar hyperglycemic syndrome state have been carried out from different teams but all of them have been made in Abidjan. This case we reported, diagnosed in the centre of the Côte d'Ivoire.

Patient referred from a private hospital in a fever context with fasting glycemia at $101.95 \mathrm{mmol} / \mathrm{l}$. The onset of symptomatology began one week before his admission by general pains and headache. One day before admission, occurred a weak of conscious such as coma that motivated his admission in hospital. In order to get a good therapy, he has been evacuated in the medical school of Bouaké. At admission, we notified severe hyperglycemia $101.95 \mathrm{mmol} / \mathrm{l}$ associated with hyperuremia at $2.75 \mathrm{~g} / \mathrm{l}$, hypercreatininemia at $125.5 \mathrm{mg} / \mathrm{l}$, massive glycosuria and only just a weak presence of ketonuria. Related to electrolytes, exams showed: hypokaliemia $(3.30 \mathrm{mEq} / \mathrm{l})$ and normal value of natremia $(143 \mathrm{mEq} / \mathrm{l})$. These values permitted us to calculate osmolality which was estimated to $440.41 \mathrm{mosm} / \mathrm{l}$. On the basis of the laboratory results and clinical examination, the diagnosis of hyperglycemic and hyperosmolar syndrome was confirmed. Moreover, fever at $39^{\circ} \mathrm{C}$ could be the primum movens of this complication and as well as a sign of infectious complications. Probably originate from lung and inherent to this disease. Rapidly fatal evolution of this case don't allow us to lead other investigations precisely X-ray; although infectious syndrome seemed to be the case of the triggering of the hyperosmolar hyperglycemic state (HHS).
\end{abstract}

Keywords: Hyperosmolar Hyperglycemic state, Inaugural, Coma, Diabetes.

\section{Introduction}

According to the recent previsions of World health Organization (WHO), the rate of this disease increased importantly during these latest years and outlooks for the forthcoming years are not better. This rate is more important in the North of America and Europe. In Africa, particularly in West Africa this disease is more and more confirmed. In our practice, if the diagnosis is easy it isn't the case for the treatment and for the monitoring because of the complications those appeared certainly after many years of evolution such as diabetic ketoacidosis (DKA) or hyperosmolar hyperglycemic state (HHS). If the treatment of DKA is known and the issue is favorable commonly, it's not the case of HHS. This complication is less frequent and occurs in particular circumstances. ${ }^{1}$

The hyperosmolar hyperglycemic state (HHS) is a syndrome characterized by severe hyperglycemia, hyperosmolality, and dehydration in the absence of ketoacidosis. The exact incidence of HHS is not known, but it is estimated to account for $1 \%$ of hospital admissions in patients with diabetes. ${ }^{2}$ Most cases of HHS are seen in elderly patients with type 2 diabetes; however, it has also been reported in children and young adults. ${ }^{3}$ The global mortality rate is estimated to be as high as $20 \%$, which is about 10 times higher than the mortality in patients with diabetic ketoacidosis (DKA) ${ }^{4-6}$ The prognosis is determined by the severity of dehydration, presence of comorbidities, and advanced age. $5,7,8$
It is not easy to distinguish DKA and HHS from a patient's history because of their similar characteristic features. HHS presents as severe hyperglycemia, hyperosmolality, with no evidence of severe ketosis or acidosis. Although HHS is a rare presentation of childhood diabetes, the importance of proper management cannot be emphasized enough due to the high mortality rate. ${ }^{9,10}$

In Côte d'Ivoire, few works related to hyperosmolar hyperglycemic syndrome state have been carried out from different teams but all of them have been made in Abidjan. Lokrou et al. ${ }^{11}$ have conducted many works concerning diabetes and its complications in Abidjan and their results concentrated in one town; don't argue the trend in the country.

This case we reported, diagnosed in the centre of the Côte d'Ivoire, is an unexpected discovery of an important hyperglycemia surroundings $101.95 \mathrm{mmol} / \mathrm{l}$ occurred suddenly by a patient aged 48 years old without any past record known precisely type 2 diabetes. This uncommonly circumstance of HHS discovering, has aroused our interest and justified this work.

\section{Case Description}

Patient referred from a private hospital in a fever coma state $\left(39^{\circ} 5 \mathrm{C}\right)$ with fasting glycemia at $101.95 \mathrm{mmol} / \mathrm{l}$. The onset of symptomatology began one week before his admission by general pains and headache growing into a fever context. One day before admission, occurred a weak of conscious such as coma 
that motivated his admission in hospital. In order to get a good therapy, he has been evacuated in the medical school of Bouaké.

A forty eight years old, man, without particular report knew admitted to medical emergency for monitoring and treatment of fever coma evolves for 24 hours. No personal history or family history of endocrine disease including mellitus diabetes was reported. At admission, the exam showed: temperature $40^{\circ} \mathrm{c}$, respiratory rate: 28 beats $/ \mathrm{min}$, blood pressure: 90/60 mmHg. He looked cachectic and lethargic, his mental status was alert, sensation was intact, and motor strength was weak revealing a deficit difficult to appreciate because of the coma. We noted located convulsions on the face together with a weak reaction of pupils and signs of global dehydratation.

Focused on this presentation of fever coma out of trauma, biological investigations were done, within different parameters prescribed figured: glycemia, urea, creatininemia, electrolytes $(\mathrm{Na}+, \mathrm{K}+, \mathrm{Cl}-)$; blood numeration, quantitative buffy coat (QBC) and glycosuria and ketonuria in urine. At admission, we notified severe hyperglycemia $101.95 \mathrm{mmol} / \mathrm{l}$ associated with hyperuremia at $45.83 \mathrm{mmol} / \mathrm{l}$, hypercreatininemia at $1114.44 \mu \mathrm{mol} / 1$, massive glycosuria and only just a weak presence of ketonuria (Table 1). Related to electrolytes, exams showed: hypokaliemia $(3.30 \mathrm{mEq} / \mathrm{l})$ and normal value of natremia $(143 \mathrm{mEq} / \mathrm{l})$. These values permitted us to calculate osmolality which was estimated to $440.41 \mathrm{mosm} / \mathrm{l}$. On the basis of the laboratory results and clinical examination, the diagnosis of hyperglycemic and hyperosmolar syndrome was confirmed. Intensive intravenous fluid and regular insulin were administrated and laboratory explorations were performed every two hours in order to oversee the evolution by checking and modulating parameters changes (table 2). Thus, glycemia, natremia, kaliema, uremia, creatininemia, glycosuria and ketonuria have been regularly meseared. Under insulinotherapy and hydratation, glycemia decreased from $101.95 \mathrm{mmol} / 1$ to $83.25 \mathrm{mmol} / 1$ two hours after onset, then $66.6 \mathrm{mmol} / 1$ and lastly $54.39 \mathrm{mmol} / \mathrm{l}$ at the sixth hour. Contrary to this trend, uremia and creatininemia increased gradually before stabilization. We noted reduction of kaliemia while natremia remained steady. Overall, we observed a HHS with decreasing value of osmolality value during the monitoring. Awaiting results to follow and perform the therapy, death unfortunately occurs in the same day surroundings $22 \mathrm{H} 30 \mathrm{~min}$.

Table 1: Laboratory results of the case at 2 pm

\begin{tabular}{|l|c|c|}
\hline Parameters & Results & References \\
\hline Blood & $101.95 \mathrm{mmol} / \mathrm{l}$ & $3.60-6.10 \mathrm{mmol} / \mathrm{l}$ \\
\hline Glycemia & $15.5 \%$ & $<5.6 \%$ \\
\hline HbA1C & $45.83 \mathrm{mmol} / \mathrm{l}$ & $2.77-8.33 \mu \mathrm{mol} / \mathrm{l}$ \\
\hline Urea & $1114.44 \mu \mathrm{mol} / \mathrm{l}$ & $53.28-106.56 \mu \mathrm{mol} / \mathrm{l}$ \\
\hline Creatininemia & $143 \mathrm{mEq} / \mathrm{l}$ & $135-155 \mathrm{mEq} / \mathrm{l}$ \\
\hline $\mathrm{Na}+$ & $3.30 \mathrm{mEq} / \mathrm{l}$ & $3.6-5.5 \mathrm{mEq} / \mathrm{l}$ \\
\hline $\mathrm{K}+$ & négative & - \\
\hline QBC & $11.18,10^{3} / \mathrm{ul}$ & $4.5-10.5,10^{3} / \mathrm{ul}$ \\
\hline WBC & $440.41 \mathrm{mOsm} / 1$ & $292-308 \mathrm{mOsm} / 1$ \\
\hline Osmolality & \multicolumn{2}{|c|}{} \\
\hline Urine & ++++ & 0 \\
\hline Glycosuria & \pm & 0 \\
\hline Urine ketones & \multicolumn{2}{|c|}{}
\end{tabular}

Table 2: Evolution of value every 2 hours

\begin{tabular}{|l|c|c|c|}
\hline \multicolumn{1}{|c|}{ Parameters } & Value at 4pm & Value at 6 pm & Value at 8pm \\
\hline Glycemia & $83.25 \mathrm{mmol} / \mathrm{l}$ & $66.6 \mathrm{mmol} / \mathrm{l}$ & $54.39 \mathrm{mmol} / 1$ \\
\hline Uremia & $46.66 \mathrm{mmol} / \mathrm{l}$ & $43.33 \mathrm{mmol} / 1$ & $44.16 \mathrm{mmol} / 1$ \\
\hline Creatininemia & $1154.4 \mu \mathrm{mol} / \mathrm{l}$ & $1136.64 \mu \mathrm{mol} / 1$ & $1243 \mu \mathrm{mol} / \mathrm{l}$ \\
\hline Kaliemia & $3,50 \mathrm{mEq} / \mathrm{l}$ & $3,45 \mathrm{mEq} / 1$ & $3,35 \mathrm{mEq} / \mathrm{l}$ \\
\hline Natremia & $142 \mathrm{mEq} / 1$ & $140 \mathrm{mEq} / \mathrm{l}$ & $145 \mathrm{mEq} / 1$ \\
\hline Glycosuria & ++++ & ++++ & ++++ \\
\hline Urine ketones & \pm & \pm & \pm \\
\hline Osmolality & $420.65 \mathrm{mOsm} / 1$ & $396.82 \mathrm{mOsm} / 1$ & $395.24 \mathrm{mOsm} / 1$ \\
\hline
\end{tabular}

\section{Discussion}

This case highlighted the lack of sanitary oversee in our practice. Several people don't receive medical assistance and much of them get many financial problems that represent a burden for the population in our undeveloped countries. This unhappy situation is frequent but mostly evolves without to be diagnosed. This case, reported is a typical presentation of HHS as 
describe in literature including serum osmolality above 400mosmol/1, serious neurological injuries and severity of dehydratation. In addition to these perturbations, we perceived renal dysfunction markedly by renal failure probably inorganic might the consequence of dehydratation state. The dissociation of urea and creatininemia justifies the mechanism of incoming renal failure. Indeed, urea increasingly is more important than creatininemia. Serum urea enhance quickly because of the capacity of the healthy tubules in the process of water and salt reabsorption, making appears a high concentration of urea in the tubules and arousing its reabsorption. This phenomenon may be due to severe water losses by renal or extra renal way. The severe osmotic polyuria could be related to an important salt elimination, and administration of salt diuretic is often found as the cornerstone of HHS. It could be due to excessive administration of osmoles through venous route like perfusion of hypertonic solution. Lastly it might be induce by important extrarenal losing of fluid. Correction of this trouble needs a rapid administration of fluid by keeping sufficient renal perfusion.

The high value of $\mathrm{HbA1C}$ might justify the chronicity of hyperglycemia state in which lived the patient prior to his admission by ignorance or negligence. Diabetes mellitus, regardless the type can complicate itself during its evolution under several modalities. HHS is the less frequent type of complication observed and its occurrence could resulted from many epidemiological and therapeutical criteria that didn't obey our patient aged 48 years old. In fact, according to Hua-Fen et al., ${ }^{1}$ HHS could appeared most often about patient above 60 years old, DKA usually occurs in younger, lean patients with type 1 diabetes and develops within a day or so, whereas HHS is more likely to occur in older, obese patients with type 2 diabetes and can take days or weeks to fully develop. In addition, HHS usually occurs in elderly diabetic patients, often those with decreased renal function who do not have access to water. ${ }^{12-14}$ The progressing dehydration leads to deteriorated renal function, reducing the capacity of the kidney to excrete glucose and further aggravating the hyperglycemic state. The reason for the absence of significant ketosis in this syndrome has been speculated by many investigators. Joffe and associates suggested that the lack of ketosis may be explained by the metabolism of incoming free fatty acid along non-ketogenic pathways in the liver. ${ }^{15}$ Gerich et al. reported that dehydration and hyperosmolality themselves suppress lipolysis, thus contributing to the non-ketotic syndrome. ${ }^{16}$

Moreover, fever at $39^{\circ} \mathrm{C}$ could be the primum movens of this complication and as well as a sign of infectious complication. Rapidly fatal evolution of this case doesn't allow us to lead other investigations. Infection remains the most important precipitating factor in the development of DKA and HHS. In 20\%-
$25 \%$ of cases, infections are the first manifestations of previously undiagnosed diabetes mellitus. ${ }^{17}$ Omissions or inadequate insulin doses are frequent precipitating factors, particularly for DKA. ${ }^{18}$ Old age, ${ }^{12-14,19,20}$ cardiovascular disease ${ }^{21}$ and infection ${ }^{19}$ have been reported to be associated with higher risks of casefatality in previous studies, but most of them failed to differentiate specific types of patients' cardiovascular diseases and infections in more detail. In addition, prognosis for the patients with HHS also tended to be worse for individuals with advanced age or severe comorbidity. ${ }^{21}$ Moreover, compared to that of DKA, the case-fatality rate of HHS was much higher varying from 12 to $46 \% .^{22}$

The treatment based on rehydratation, insulinotherapy and intensive monitoring has been done but in spite of this therapy the outcome has been fatal to the patient the same day, six hours after his admission. HHS usually causes greater morbidity and mortality than DKA, depending on the severity of dehydration, hyper-osmolality, and patient age..$^{23-25}$

Pinies et $\mathrm{al}^{26}$ reported 132 cases of HHS, according to their report, the mortality rate was $16.9 \%$, and the incidence rate of complications associated with HHS were as follows: septic shock, 5.4\%; cardiac failure, $2.3 \%$; digestive bleeding, $1.5 \%$; stroke, $1.5 \%$; pulmonary embolism, $0.77 \%$; and hypoglycemia due to insulin therapy, $0.77 \%$. A few cases of HHS associated with rhabdomyolysis and acute kidney injury have been reported, ${ }^{27}$ but their frequency is unclear. In a study by Singhal et al, the incidence of acute renal failure in diabetic emergencies (diabetic ketoacidosis and hyperosmolar non-ketotic diabetic coma) was $25 \% .{ }^{18}$ As dehydration is more severe in HHS than in diabetic ketoacidosis, the incidence of acute renal failure in HHS may be higher. HHS is reported to be a rare cause of rhabdomyolysis the electrogenic sodium pump is inhibited by hyperosmolar states, acidosis, hypernatremia, and potassium deficiency, as well as by decreases in intramuscular energy supply due to insulin deficiency. ${ }^{29}$

\section{Conclusion}

Making the diagnosis of mellitus diabetes during the state of complication is not so uncommon in our daily practice, however the conditions of a good therapy are not always guaranteed which lead in the most cases to fatal issue. In order to prevent and reduce death related to chronic diseases and particularly mellitus diabetes many actions have to be conduct so as to screen early this disease in our population and ensure a good treatment. Since the prognosis of hyperosmolar hyperglycemic syndrome is more serious than the other manifestations, we greatly recommend information and sensibilization attending to the population about this disease in order to make early diagnosis and enhance the treatment monitoring. 


\section{References}

1. Hua-Fen Chen, Chih-Yuan Wang, Hsin-Yu Lee et al. Short-Term Case Fatality Rate and Associated Factors among Inpatients with Diabetic Ketoacidosis and Hyperglycemic Hyperosmolar State: A Hospital-Based Analysis over a 15-Year Period. Inter Med. 2010;49:729737.

2. Fishbein HA, Palumbo PJ. Acute metabolic complications in diabetes. In Diabetes in America. National Diabetes Data Group, National Institutes of Health. 1995 Jan.; $2^{\text {ème }}$ Ed. p. 283-291.

3. Rosenbloom AL. Hyperglycemic hyperosmolar state: an emerging pediatric problem. J Pediatrics 2010 Feb; 156 (2):180-184

4. Milionis HJ, Elisaf MS. Therapeutic management of hyperglycaemic hyperosmolar syndrome. Expert Opin Pharmacother. 2005 Sep;6(11):1841-9.

5. Kitabchi AE, Umpierrez GE, Miles JM, Fisher JN. Hyperglycemic crises in adult patients with diabetes. Diabetes Care. 2009 Jul;32 (7):1335-43.

6. Fadini GP, de Kreutzenberg SV, Rigato M, et al. Characteristics and outcomes of the hyperglycemic hyperosmolar non-ketotic syndrome in a cohort of 51 consecutive cases at a single center. Diabetes Res Clin Pract. 2011 Nov; 94(2):172-9.

7. Wachtel TJ, Silliman RA, Lamberton P. Prognostic factors in the diabetic hyperosmolar state. J Am Geriatr Soc. 1987 Aug;35(8):737-41.

8. Umpierrez GE, Kelly JP, Navarrete JE, Casals MM, Kitabchi AE. Hyperglycemic crises in urban blacks. Arch Intern Med. 1997 Mar;157(6):669-75.

9. Cho YM, Park BS, Kang MJ. A case report of hyperosmolar hyperglycemic state in a 7-year-old child. Medicine. 2017 Jun;96(25):1-4.

10. Pasquel FJ, Umpierrez GE. Hyperosmolar hyperglycemic state: a historic review of the clinical presentation, diagnosis, and treatment. Diabetes Care. 2014 Nov;37(11):3124-31.

11. Lokrou A., Taki N.R., Abodo J. hyperosmolar hyperglycemic syndrome of early diagnosis presentation and prognosis of a series from Ivory Coast. Elsevier. $2001 \mathrm{Feb} ; 4$ (1):83-7.

12. Wachtel TJ, Silliman RA, Lamberton P. Prognostic factors in the diabetic hyperosmolar state. $J$ Am Geriatr Soc. 1987 Aug;35(8):737-41.

13. Trence DL, Hirsch IB. Hyperglycemic crises in diabetes mellitus type 2. Endocrinol Metab Clin North Am. 2001 Dec;30 (4):817-31.

14. Malone ML, Gennis V, Goodwin JS. Characteristics of diabetic ketoacidosis in older versus younger adults. $J \mathrm{Am}$ Geriatr Soc. 1992 Nov;40(11):1100-4.

15. Joffe BI, Seftel HC, Goldberg R, Van As M, Krut L, Bersohn I. Factors in the pathogenesis of experimental nonketotic and ketoacidotic diabetic stupor. Diabetes. 1973 Sep;22 (9):653-7.

16. Gerich J, Penhos JC, Gutman RA, Recant L. Effect of dehydration and hyperosmolarity on glucose, fatty acid and ketone body metabolism in the rat. Diabetes. 1973 Apr;22(4):264-71.
17. Charlson ME, Pompei P, Ales KL, MacKenzie R. A new method of classifying prognostic comorbidity in longitudinal studies: developmental and validation. $J$ Chron Dis. 1987;40(5):373-83.

18. Jeldres C, Isbarn H, Capitanio U, et al. Development and external validation of a highly accurate nomogram for the prediction of perioperative mortality after transurethral resection of the prostate for benign prostatic hyperplasia. J Urol. 2009;182:626-32.

19. Ko SH, Lee WY, Lee JH, et al. Clinical charteristics of diabetic ketoacidosis in Korea over past two decades. Diabet Med. 2005 Apr;22(4):466-9.

20. $\mathrm{Yu} \mathrm{EH}, \mathrm{Wu}$ TF. Clinical profiles in adult diabetic ketoacidotic patients in a tertiary medical referral medical center in southern Taiwan. J Formos Med Assoc. 1998;97:85-89.

21. Krentz AJ, Nattrass M. Acute metabolic complications of diabetes: diabetic ketoacidosis, hyperosmolar non-ketotic hyperglycemia and lactic acidosis. Am J Epidemiol. 1983;117:551- 8 .

22. Delaney MF, Zisman A, Kettyle WM. Diabetic ketoacidosis and hyperglycemic hyperosmolar nonketotic syndrome. Endocrinol Metab Clin North Am. 2000 Dec;29(4):683-705.

23. Chiasson JL, Aris-Jilwan N, Bélanger R et al. Diagnosis and treatment of diabetic ketoacidosis and the hyperglycemic hyperosmolar state. CMAJ. $2003 \mathrm{Apr}$. 1;168 (7):859-66.

24. Adrogue HJ, Wilson H, Boyd AE, Suki WN, Eknoyan G. Plasma acid base patterns in diabetic ketoacidosis. $N$ Engl J Med. 1982 Dec;307(26):1603-10.

25. Izumi T, Shimizu E, Imakiire T et al. A Successfully Treated Case of Hyperosmolar Hyperglycemic State Complicated with Rhabdomyolysis, Acute Kidney Injury, and Ischemic Colitis. Intern Med. 2010;49 (21):2321-6.

26. Pinies JA, Cairo G, Gaztambide S, Vazquez JA. Course and prognosis of 132 patients with diabetic non ketotic hyperosmolar state. Diabete Metab. 1994;20:43-48.

27. Ka T, Takahashi S, Tsutsumi Z, Moriwaki Y, Yamamoto T, Fukuchi M. Hyperosmolar non-ketotic diabetic syndrome associated with rhabdomyolysis and acute renal failure: a case report and review of literature. Diabetes Nutr Metab. 2003;16:317-22.

28. Singhal PC, Abramovici M, Ayer S, Desroches L. Determinants of rhabdomyolysis in the diabetic state. Am J Nephrol. 1991;11:447-50.

29. Singhal PC, Schlondorff D. Hyperosmolal state associated with rhabdomyolysis. Nephron. 1987;47:2024.

How to cite this article: DERE K.A.L, Kouame A.B, KOFFI K.G., Kahissié M, George T.G,. A case of inaugural hyperosmolar diabetic coma reported from Ivory Coast. Int J Clin Biochem Res. 2018;5(3):497-500. 